\title{
Home Site Fidelity in Black Rockfish, Sebastes melanops, Reintroduced into a Fjord Environment
}

\author{
Jeff Marliave ${ }^{1}$, Alejandro Frid ${ }^{1, *}$, David W. Welch ${ }^{2}$, and Aswea D. Porter ${ }^{2}$ \\ ${ }^{1}$ Vancouver Aquarium, P.O. Box 3232, Vancouver, British Columbia V6B 3X8 Canada \\ ${ }^{2}$ Kintama Research Services Ltd., 10-1850 Northfield Road, Nanaimo, British Columbia V9S 3B3 Canada \\ *Corresponding author; email; alejfrid@gmail.com
}

Marliave, Jeff, Alejandro Frid, David W. Welch, and Aswea D. Porter. 2013. Home site fidelity in Black Rockfish, Sebastes melanops, reintroduced into a fjord environment. Canadian Field-Naturalist 127(3): 255-261.

Between December 2004 and January 2007, we studied the movements of six Black Rockfish (Sebastes melanops) that had been fitted with acoustic transmitters and reintroduced into a fjord environment at the edge of Vancouver Harbour, British Columbia. The Black Rockfish were released in December 2004 and April 2005 at a reef characterized by complex rocky structures and steep slopes; bottom depths at the site dropped from 10 to $55 \mathrm{~m}$ within a horizontal distance of only $30 \mathrm{~m}$. The reef, however, is small (approximately $4500 \mathrm{~m}^{2}$ ) and is surrounded by soft bottom habitats used infrequently by Black Rockfish. VEMCO VR2 receivers were deployed at the release site and at outlying reefs located 1 and $4 \mathrm{~km}$ away. Acoustic data suggest that one individual emigrated from the reef after 11 months of residency and a second individual disappeared abruptly after 6 weeks on the reef, possibly due to fishing mortality or emigration. The four remaining individuals appear to have confined their movements to the release site, using an area 6 to 10 times smaller than the home ranges reported for populations in lowgradient coastlines in California and Oregon.

Key Words: acoustic transmitters; animal movement; animal reintroductions; Black Rockfish; Sebastes melanops; ecological restoration; habitat effects on movement; home site fidelity; British Columbia

\section{Introduction}

Rockfishes (Sebastes spp.) are vulnerable to overexploitation (Love et al. 2002; Berkeley et al. 2004), and data on their movements and home site fidelity are important for managing the genus (Freiwald 2012). For instance, whether networks of marine reserves succeed in restoring exploited populations may depend on the extent to which dispersing juveniles and resident adults confine their movements to protected areas (Moffitt et al. 2009).

For some rockfish species, the distances moved by adults may depend on habitat. The home ranges of Copper Rockfish (Sebastes caurinus) and Quillback Rockfish (S. maliger), for example, span less than $30 \mathrm{~m}^{2}$ in structurally complex boulder piles (Matthews 1990a, $1990 \mathrm{~b}$ ) but cover 1.5 to $2.5 \mathrm{~km}^{2}$ in simpler substrates, such as low-relief sandstone composite (Tolimieri et al. 2009). These patterns are potentially explained by the higher density of refuges and perhaps greater prey abundance in the more complex habitats (Frid and Marliave 2010).

In Black Rockfish (Sebastes melanops) populations, some adults emigrate several hundred kilometres from the sites where they were tagged, but most individuals remain near their tagging locations (Green and Starr 2011 and references within). In low-gradient coastlines of California and Oregon, where Black Rockfish in shallow habitats (10 $\mathrm{m}$ bottom depths) must move horizontally 0.5 to $>1 \mathrm{~km}$ to reach deeper habitats $(>20 \mathrm{~m}$ bottom depths), adult home ranges averaged $0.25 \mathrm{~km}^{2}$ in California (Green and Starr 2011) and $0.55 \mathrm{~km}^{2}$ in Oregon (Parker et al. 2007).
Use of space by Black Rockfish in fjords, where bottom depths drop from shallow to deep habitats within a few horizontal metres, is poorly understood. We hypothesized that, in this environment, Black Rockfish would confine their movements to habitat patches much smaller than the home ranges reported for individuals in lowgradient coastlines.

We tested this hypothesis during a restoration project in which Black Rockfish were surgically implanted with acoustic transmitters and transplanted from the west coast of Vancouver Island to Point Atkinson, a fjord environment at the edge of Vancouver Harbour, British Columbia (Figure 1). Point Atkinson is suitable for testing our hypothesis: at that site, rocky habitat preferred by rockfish (Love et al. 2002) encompasses only $4500 \mathrm{~m}^{2}$ and is surrounded by soft substrates, which Black Rockfish use infrequently (Johnson et al. 2003). Additionally, bottom depths at the Point Atkinson reef drop from $10 \mathrm{~m}$ to $55 \mathrm{~m}$ within a horizontal distance of only $30 \mathrm{~m}$ (Figure 2 ). Copper Rockfish and Quillback Rockfish are common species on rocky habitats of the area and occur at the three study reefs (JM, unpublished data), indicating that these sites provide suitable habitats for benthic-dwelling rockfishes.

\section{Study Site and Methods}

Our acoustic transmitter project was the final stage in transplanting a 1996 cohort of Black Rockfish from the west coast of Vancouver Island to the east side of Point Atkinson, British Columbia (Figure 1). Point Atkinson is a popular sport angling reef where Black Rockfish had been depleted. Diving biologists docu- 


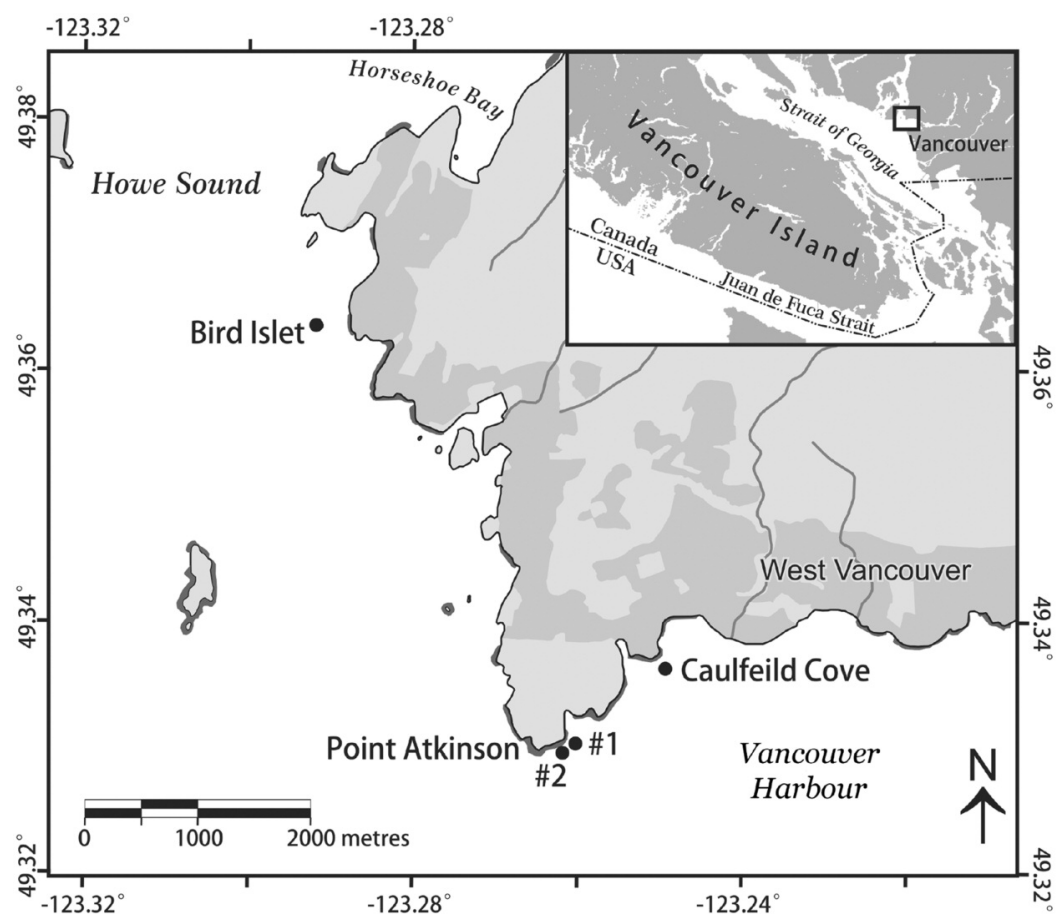

Figure 1. Map of the study site at Point Atkinson, British Columbia. Filled circles at Bird Islet, Point Atkinson, and Caulfeild Cove indicate receiver locations.

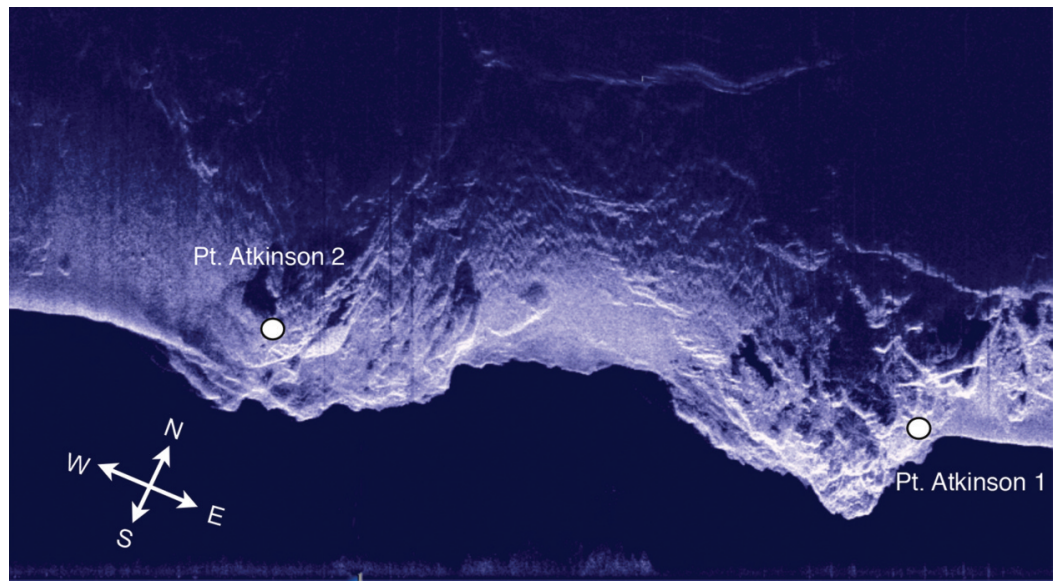

FIgURE 2. Sidescan sonar image of the Point Atkinson reef and VR2 receivers, as seen from the surface looking down at the reef. Bottom depths drop from shallowest at the top to deepest at the bottom of the image. Due to a "shadow" in sonar reading, depths deeper than $33 \mathrm{~m}$ (which encompass boulder habitat) appear as a black band at the bottom of the image. Receivers were approximately $45 \mathrm{~m}$ apart; the portion of reef depicted is $\approx 2300 \mathrm{~m}^{2}$.

mented schools of Black Rockfish at the site in the 1960s, but noted the species' absence by the early 1970s (Andy Lamb, personal communication). The disappearance of Black Rockfish from Point Atkinson likely coincided with the wider extirpation of the species throughout Vancouver Harbour and adjacent areas in Howe Sound. As described earlier, suitable rocky habi- tat at Point Atkinson is confined to a $4500 \mathrm{~m}^{2}$ reef with a steep depth gradient (Figure 2).

Black Rockfish were captured as young-of-the-year in Ucluelet, British Columbia, in 1996 and reared at the Vancouver Aquarium. On November 6, 1997, staff from the Washington Department of Fish and Wildlife tagged 252 of these Black Rockfish with coded wire 
tags (NMT INC Northwest Marine Technology, Shaw Island, Washington, USA); these yearlings were released at the east side of Point Atkinson between November 1997 and January 1998. Observations by divers after the initial releases suggested that some transplanted fish established residence in the structurally complex rocky reef of Point Atkinson (JM, personal observations). In response to these findings, in June 1998 Fisheries and Oceans Canada temporarily created at that site a small protected area $(100 \mathrm{~m} \times 80 \mathrm{~m})$ where fishing was prohibited.

A subset of Black Rockfish from the 1996 cohort was reared to sexual maturity at the Vancouver Aquarium. VEMCO acoustic transmitters (VEMCO, Bedford, Nova Scotia) were implanted in the abdominal cavities of 4 of these Black Rockfishes on 14 November 2004 and 6 of these Black Rockfishes on 22 March 2005 (total 10) (Table 1). Transmitter size varied according to fish size (Table 1).

Surgical implantation was performed at the Vancouver Aquarium. Tetracycline was administered using a hypodermic syringe a day before surgery and at the time of surgery. A preoperative anaesthetic of metomidate hydrochloride (Aquacalm, Western Chemical Inc., Ferndale, Washington) (10 minutes at $1 \mathrm{mg} / \mathrm{L}$ ) was followed by full anaesthesia in tricaine methane sulfonate (MS222, 8 minutes at $70 \mathrm{mg} / \mathrm{L}$ ). Surgical implantation of the transmitters was performed while recirculated, aerated seawater with a low dose level (50 $\mathrm{mg} / \mathrm{L}$ ) of MS222 was pumped over the gills. Incisions were closed with two dissolving sutures of Ethicon PDS-II 2-0 monofilament polydioxanone with an FS-2 cutting needle (Ethicon, Somerville, New Jersey), and fish were then isolated in a dark recovery tank.

After three to five weeks of surgical recovery (Table 1), the Black Rockfish with surgically implanted transmitters were transported under light MS222 anaesthesia $(25 \mathrm{mg} / \mathrm{L})$ in aerated seawater to Point Atkinson and placed inside a custom-made $1 \mathrm{~m}^{3}$ zippered cage that divers had tethered at a depth of $18 \mathrm{~m}$ near the Point Atkinson release site 1 (Figure 1). Fish were acclimated within the cage for 4-6 days prior to their release (Table 1). During the acclimation period, Sunflower Seastars (Pycnopodia helianthoides) killed 4 Black Rockfish through the cage meshes, reducing the sample size to 6 fish with surgical implants (Table 1). Three Black Rockfish were released in December 2004 and 3 were released in April 2005.

Four VEMCO VR2 acoustic receivers (VEMCO, Bedford, Nova Scotia) were deployed at the study area: two at opposite ends of the Point Atkinson reef (approximately $45 \mathrm{~m}$ apart) where submarine peaks blocked the line of sight between receivers (Figure 2), one at the Bird Islet rocky reefs, $4 \mathrm{~km}$ northwest of Point Atkinson, and one at the Caulfeild Cove reef, $1 \mathrm{~km}$ northeast of Point Atkinson (Figure 1 and Table 2). Scuba divers chained the receivers to the bottom and attached under-

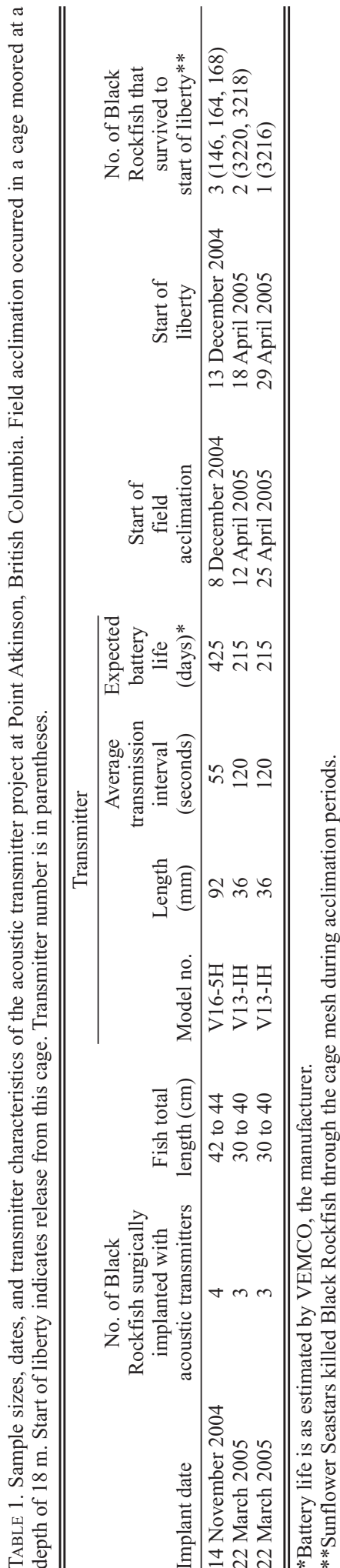


TABle 2. Deployment periods for acoustic receivers at Caulfeild Cove, Point Atkinson (release site was Point Atkinson 1), and Bird Islet, British Columbia. Note that receivers VR2 4666, VR2 4667, and VR2 4669 were deployed at different sites during different dates. See Figure 1 for site locations.

\begin{tabular}{|c|c|c|c|c|}
\hline Site & Depth (m) & Receiver ID & Date deployed & Date data recovered \\
\hline \multirow{3}{*}{ Caulfeild Cove } & 9 & VR2 4666 & 23 December 2004 & 3 February 2005 \\
\hline & & VR2 4666 & 7 April 2005 & 27 July 2005 \\
\hline & & VR2 4666 & 8 September 2005 & 14 March 2006 \\
\hline \multirow[t]{4}{*}{ Point Atkinson 1} & 30 & VR2 4668 & 22 December 2004 & 3 February 2005 \\
\hline & & VR2 4668 & 7 April 2005 & 29 June 2005 \\
\hline & & VR2 4668 & 23 August 2005 & 6 April 2006* \\
\hline & & VR2 4667 & 5 October 2006 & 31 January 2007 \\
\hline \multirow[t]{5}{*}{ Point Atkinson 2} & 17 & VR2 4667 & 7 January 2005 & 3 February 2005 \\
\hline & & VR2 4667 & 18 April 2005 & 29 June 2005 \\
\hline & & VR2 4667 & 10 August 2005 & 5 April $2006^{* *}$ \\
\hline & & VR2 4669 & 25 April 2006 & 16 August 2006 \\
\hline & & VR2 4666 & 5 October 2006 & 29 January 2007 \\
\hline \multirow[t]{3}{*}{ Bird Islet } & 19 & VR2 4669 & 6 January 2005 & 3 February 2005 \\
\hline & & VR2 4669 & 18 April 2005 & 27 July 2005 \\
\hline & & VR2 4669 & 8 September 2005 & 14 March 2006 \\
\hline
\end{tabular}

* Memory filled prior to data recovery on 13 December 2005

**Memory filled prior to data recovery on 31 October 2005.

water mooring buoys which kept receivers $3 \mathrm{~m}$ above the bottom.

Data from receivers at Point Atkinson were downloaded four or five times between December 2004 and January 2007. Receivers were out of the water for periods of several weeks during each data download (Table 2). Additionally, computer memory for the Point Atkinson receivers filled to capacity during fall 2005 ; these receivers did not resume recording until after they had been serviced in the spring of 2006. Receivers located at Bird Islet and Caulfeild Cove operated from December 2005 through March 2006 with three recovery periods for data download (Table 2).

\section{Results}

We recorded a total of 1519367 detections of 6 Black Rockfish over the cumulative duration of receiver de- ployments (see Table 2). All detections were confined to the two detection sites located at Point Atkinson; no signals from the 6 Black Rockfish with surgically implanted acoustic transmitters were detected at the outlying locations of Bird Islet or Caulfeild Cove (Figure 1).

Four of the 6 Black Rockfish with surgically implanted acoustic transmitters were detected almost continuously during the periods in which transmitter batteries were expected to be operational and receivers were deployed and had memory space available (Figure 3). (Two Black Rockfish, transmitter numbers 3218 and 3216, were detected for 15 months beyond the expected battery life, but such extended battery life is not predictable and is not guaranteed by the manufacturer.) One Black Rockfish (transmitter number 168) disappeared after only 6 weeks at liberty. A second Black

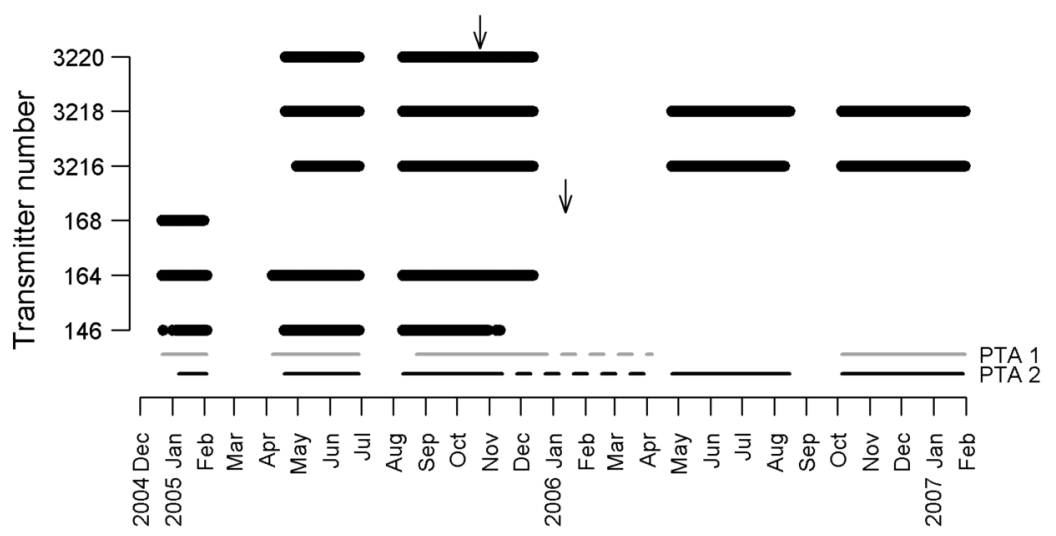

FiguRE 3. Presence and absence of Black Rockfish (Sebastes melanops) with surgically implanted acoustic transmitters detected by the two receivers at Point Atkinson, British Columbia (data are combined). Thin lines at the bottom of the graph indicate the periods during which receivers were deployed; dotted lines indicate periods when the memory was full (i.e., unable to collect data). The vertical arrows indicate the expected end of transmitter battery life (see Table 1). The top arrow applies to the first three transmitters and the bottom arrow applies to the last three transmitters. 
Rockfish (transmitter number 146) was last detected in mid-November 2005, after 11 months of residency (Figure 3).

The median time between detections ranged from 0.6 to 1.8 minutes (data for all Black Rockfish pooled). Only 138 detections $(<0.01 \%)$ were spaced by more than an hour; most of these cases may have resulted from Black Rockfish hiding inside crevices where signals were blocked. The longest absences ( 5 absences of $>20$ hours) were for Black Rockfish transmitter number 146 at the start and finish of its data set, suggesting that this Black Rockfish undertook excursions away from the release site at the start of liberty, then settled at the reef for 11 months before emigrating (Figure 4). The possibility of emigration is consistent with the fact that detections of signals from Black Rockfish transmitter number 146 ended earlier than detections of signals from Black Rockfish transmitter number 164 (both transmitters were deployed simultaneously and under equal conditions of battery life and receiver availability) (Figure 3 ).

We assumed that acoustic signals emanated from live Black Rockfish, rather than from transmitters immobile on the bottom. Accordingly, we found that at Point Atkinson-where rocky structures (Figure 2) created acoustic barriers between receivers - the number of daily detections showed patterns consistent with reef-scale movements. Daily detections were highly

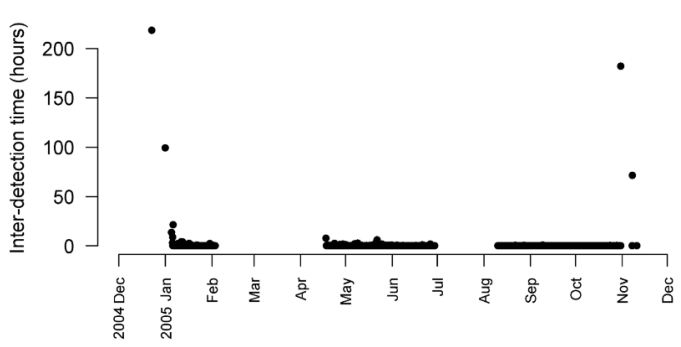

FiguRE 4. Time between detections for Black Rockfish (Sebastes melanops) transmitter number 146 with a surgically implanted acoustic transmitter at Point Atkinson, British Columbia.

variable; for some Black Rockfish, detections were at times more numerous at one receiver than the other, and this pattern reversed between receivers over periods of days or weeks (Figures 5 and 6). Although changes in the acoustic environment may have contributed to this variability, we interpret these patterns as evidence of Black Rockfish moving between positions where the rugged terrain would interfere with signal transmission to one or both receivers. This interpretation is consistent with direct observations of live Black Rockfish made by divers at Point Atkinson during the study (JM, personal observations).
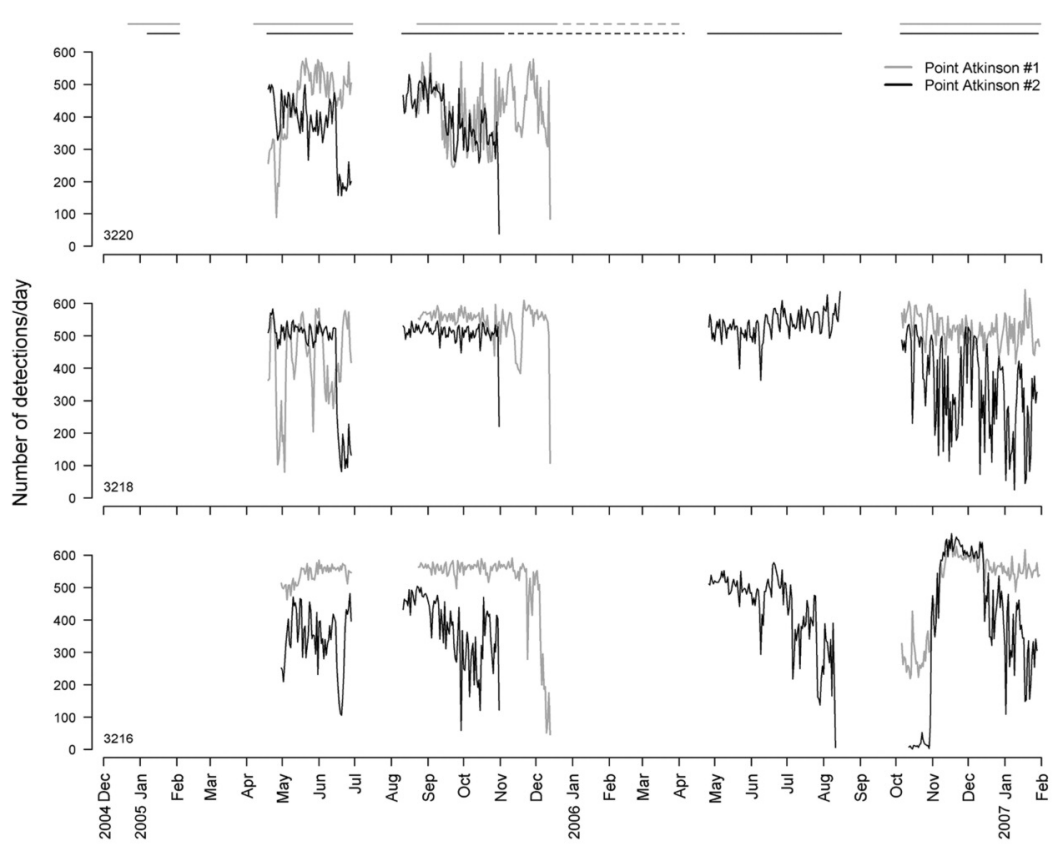

FiguRE 5. Daily number of detections made by receivers no. 1 (grey line) and no. 2 (black line) at Point Atkinson, British Columbia, of signals from Black Rockfish (Sebastes melanops) with surgically implanted acoustic transmitters that began liberty during December 2004. The transmitter numbers of the individual Black Rockfish are in the lower left corner. Horizontal lines at the top of the graph indicate the periods during which receivers were deployed; dotted lines indicate periods when the memory was full (i.e., unable to collect data). 


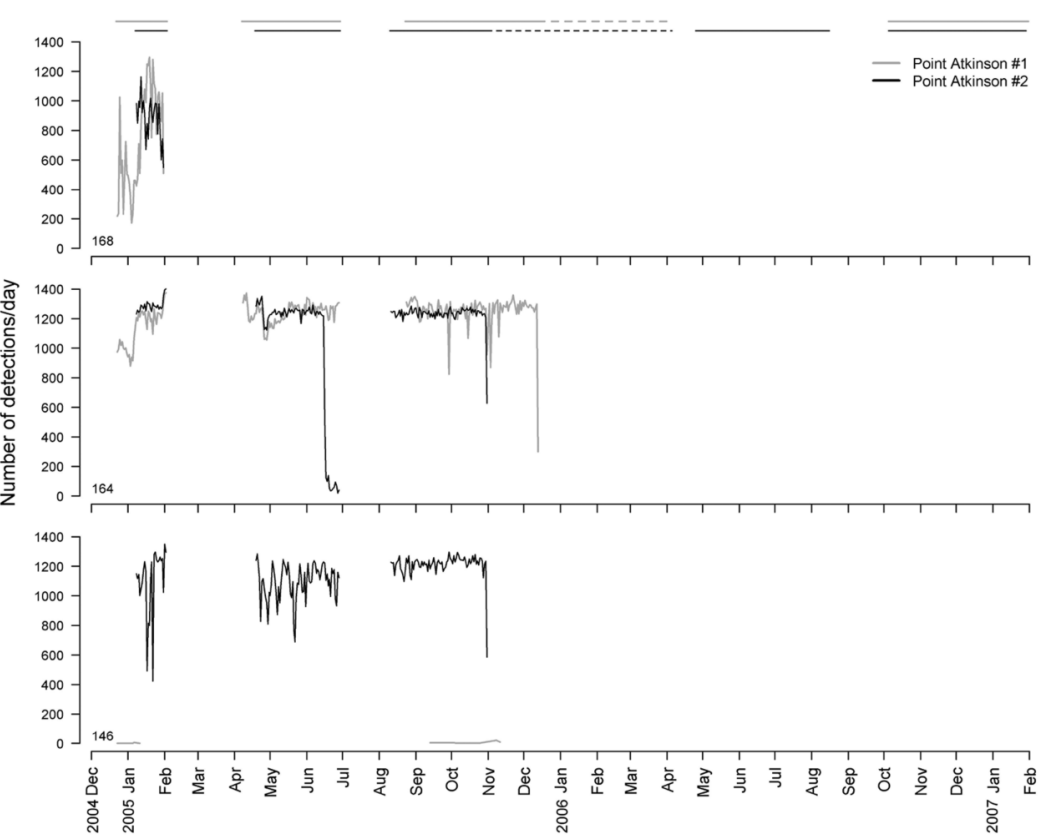

FIgURE 6. Daily number of detections made by Point Atkinson receivers no. 1 (grey line) and no. 2 (black line) of signals from Black Rockfish (Sebastes melanops) with surgically implanted acoustic transmitters that began liberty during April 2005. See Figure 5 for details.

\section{Discussion}

To our knowledge, this is the first study to report home site fidelity in Black Rockfish with surgically implanted acoustic transmitters in a fjord environment. Our results suggest that 4 of 6 individuals confined their movements to a small rocky reef that spanned only approximately $4500 \mathrm{~m}^{2}$. Signals from these Black Rockfish with surgically implanted acoustic transmitters were recorded exclusively and almost continuously at the Point Atkinson reef throughout the period of expected battery life of the transmitters and whenever computer memory remained available to record detections. Signals from the 2 remaining Black Rockfish, however, indicate shorter periods of residency at the reef. Signals from one individual ceased abruptly after 6 weeks on the reef, perhaps due to fishing mortality or emigration. A second individual made excursions away from the reef and appears to have emigrated after 11 months of residency.

Receivers may have recorded signals from the transmitters originating up to several hundred metres away, and such distances would exceed the dimensions of the Point Atkinson reef. Therefore, we cannot exclude the possibility that Black Rockfish spent some of their time on soft substrates immediately adjacent to the reef rather than on the reef itself. However, extensive use of the adjacent soft-bottomed habitat seems unlikely because prior studies indicate that Black Rockfish (Johnson et al. 2003) and other Sebastes species (Love et al. 2002; O'Farrell et al. 2009) select rocky habitats and use soft substrates infrequently. This does not preclude the possibility that Black Rockfish may emigrate by crossing such areas, and our study suggests that such behaviour does occur.

We suggest that most Black Rockfish remained within the small area of the Point Atkinson reef because the site provided structurally complex habitat and included a $45 \mathrm{~m}$ range of bottom depths within 30 horizontal metres. Our results, however, cannot distinguish the extent to which home site fidelity was determined by avoidance of poor quality habitats (surrounding mudflats) rather than attraction to the high-quality habitat of the reef. Regardless of the causal mechanisms, the observations reported here contrast with those of Black Rockfish studied in low-gradient coastlines, where average home ranges are 6 to 10 times greater than the isolated habitat patch used by Black Rockfish during this study (Parker et al. 2007; Green and Starr 2011). To improve the understanding of the relationship between movements and depth gradient, future work should be done with Black Rockfish at multiple locations where rocky habitats are structurally similar yet slope angles differ.

We acknowledge that the Black Rockfish in the study were translocated as young-of-the-year and reared to maturity in captivity, and this may have altered natural movement behaviour. Studies similar to this one, therefore, should be replicated with wild-caught adults with no period in captivity. 


\section{Acknowledgements}

Animal rearing and handling protocols were approved by the Conservation and Research Committee of the Board of Governors of the Vancouver Aquarium Marine Science Centre. The study was funded by the Vancouver Aquarium and the Howe Sound Research and Conservation Group. Staff from Kintama Research surgically implanted the acoustic transmitters. We thank Claude B. Renaud and two anonymous reviewers for comments on an earlier draft.

\section{Literature Cited}

Berkeley, S. A., M. A. Hixon, R. J. Larson, and M. S. Love. 2004. Fisheries sustainability via protection of age structure and spatial distribution of fish populations. Fisheries 29: $23-32$.

Freiwald, J. 2012. Movement of adult temperate reef fishes off the west coast of North America. Canadian Journal of Fisheries and Aquatic Sciences 69: 1362-1374.

Frid, A., and J. Marliave. 2010. Predatory fishes affect trophic cascades and apparent competition in temperate reefs. Biology Letters 6: 533-536.

Green, K. M., and R. M. Starr. 2011. Movements of small adult Black Rockfish: implications for the design of MPAs. Marine Ecology Progress Series 436: 219-230.

Johnson, S., M. Murphy, and D. Csepp. 2003. Distribution, habitat, and behavior of rockfishes, Sebastes spp., in nearshore waters of southeastern Alaska: observations from a remotely operated vehicle. Environmental Biology of Fishes 66: 259-270.

Love, M., M. Yoklavich, and L. Thorsteinson. Editors. 2002. The Rockfishes of the Northeast Pacific. University of California Press, Berkley, California.
Matthews, K. R. 1990a. An experimental study of the habitat preferences and movement patterns of copper, quillback, and brown rockfishes (Sebastes spp). Environmental Biology of Fishes 29: 161-178.

Matthews, K. R. 1990b. A telemetric study of the home ranges and homing routes of copper and quillback rockfishes on shallow rocky reefs. Canadian Journal of Zoology 68: 2243-2250.

Moffitt, E. A., L. W. Botsford, D. M. Kaplan, and M. R. O'Farrell. 2009. Marine reserve networks for species that move within a home range. Ecological Applications 19: $1835-1847$.

O'Farrell, M. R., M. M. Yoklavich, and M. S. Love. 2009. Assessment of habitat and predator effects on dwarf rockfishes (Sebastes spp.) using multi model inference. Environmental Biology of Fishes 85: 239-250.

Parker, S. J., P. S. Rankin, J. M. Olson, and R. W. Hannah. 2007. Movement patterns of black rockfish (Sebastes melanops) in Oregon coastal waters. Pages 39-57 in Biology, Assessment, and Management of North Pacific Rockfishes. Edited by J. Heifetz, J. Dicosimo, A. J. Gharrett, M. S. Love, V. M. Oconnell, and R. D. Stanley. Proceedings of the Biology, Assessment, and Management of North Pacific Rockfishes (23rd Lowell Wakefield Fisheries Symposium), September 13-15, 2005, Anchorage, Alaska. Alaska Sea Grant College Program, Juneau, Alaska, and the University of Alaska, Fairbanks, Fairbanks, Alaska.

Tolimieri, N., K. Andrews, G. Williams, S. Katz, and P. S. Levin. 2009. Home range size and patterns of space use by lingcod, copper rockfish and quillback rockfish in relation to diel and tidal cycles. Marine Ecology Progress Series 380: 229-243.

Received 13 June 2013

Accepted 29 August 2013 